\title{
Evaluation of Rhombic Three Dimensional Plate in Fixation of Displaced Low Subcondylar Mandibular Fractures
}

\author{
Mahmoud F. Abu Eldahab ${ }^{1}$, Mohammad M. Shoushan', Mohammad A. Elshall', \\ Ibrahim M. Nowair
}
Original $\quad{ }^{1}$ B.D.S, Demonstrator at Oral and Maxillofacial Surgery Department, Faculty of Article
Dentistry, Tanta University.

${ }^{2}$ PhD, Professor at Oral and Maxillofacial Surgery Department, Faculty of Dentistry, Tanta University.

${ }^{3}$ PhD Assistant Professor at Oral and Maxillofacial Surgery Department, Faculty of Dentistry, Tanta University.

\begin{abstract}
PURPOSE: The aim of this study was to evaluate the rhombic three-dimensional plate in fixation of displaced low subcondylar mandibular fractures clinically and radiographically.

MATERIALS AND METHODS: This is a prospective, interventional, single armed case series study that was carried out on twelve patients with displaced low subcondylar mandibular fracture. Open reduction and internal fixation was utilized to treat those fractures using rhombic 3D plate, patients were collected from the department of Oral and Maxillofacial surgery, Faculty of Dentistry, Tanta University. All cases were treated with retromandibular approach. Post-operative evaluation: all patients underwent regular follow up for six months. The following parameters were evaluated: a. Maximal mouth opening, b. Lateral and protrusive mandibular movements, c. Chewing and occlusion, d. Clicking and tenderness of TMJ, e. Vertical height of the ramus, f. Anteroposterior angulation of the condyle.
\end{abstract}

RESULTS: 6 months after the operation, the functional parameters returned to normal, with an average mouth opening of $43.6 \mathrm{~mm}$, protrusion of $9.6 \mathrm{~mm}$, and laterotrusion of $10.5 \mathrm{~mm}$. No clicks or tender TMJ, normal function of facial nerve. Radiographic controls showed good fracture alignment, no plate fracture, bending or loose screws were observed.

CONCLUSIONS: The clinical and radiographical data suggested that the rhombic three-dimensional plate is suitable for treatment of condylar fractures and provided stable fixation.

Key Words: Low displaced condyle fractures - mandibular trauma rhombic 3d plate.

Received:1 September 2018, Accepted:4 September 2018

Corresponding Author: Mahmoud, Abu Eldahab B.D.S, Demonstrator at Oral and Maxillofacial Surgery Department, Faculty of Dentistry, Tanta University.Egypt, E-mail: mahmoudfaisel2@gmail.com

ISSN: 2090-097X, May 2018, Vol. 9, No. 2

\section{INTRODUCTION}

Mandibular fractures are the third most frequent maxillo-facial fractures after those of the nasal and zygomatic bones. Mandibular condylar neck fractures and subcondylar fractures constitute $19-29 \%$ and $62-70 \%$ of all mandibular fractures respectively. ${ }^{1,2}$

Condylar fractures deserve a special consideration apart from rest of the mandible due to their anatomical differences and healing potential. However, the sequela of the condylar injuries cannot be considered suboptimal with regard to malocclusion, reduced mouth opening, deviation of the mandible, impaired mastication, ankylosis and internal derangement. . $^{3,4}$
For decades, closed treatment has been preferred because it is easier and less invasive, and the results are comparable with no surgical complications. On the other hand it may employ varying periods of intermaxillary fixation (4 to 6 weeks) followed by aggressive physiotherapy. In addition, long-term complications like pain, arthritis, malocclusion, deviation of the mandible on opening and closing movements, temporomandibular joint dysfunction, facial asymmetry and ankylosis. ${ }^{5-7}$

The debate regarding the optimal treatment of these fractures is still open and the decision concerning appropriate intervention for every fractured condyle 
has to be made individually. Haug et al., Zide and Kent published indications for open treatment of the condyle process fractures which include malocclusion, mandibular dysfunction and abnormal relationship of the jaws. ${ }^{8,9}$

Surgical treatment of condylar neck and subcondylar region fractures involves the risk of facial nerve damage thus, surgical approach requires great experience in order to avoid injury to the facial nerve and its branches, limit the traumatic surgical manoeuvres by internal rigid fixation and obtain a wide surgical field with good illumination and undisturbed vision. Different approaches (e.g., preauricular, submandibular, retroauricular, retromandibular, transoral, or combinations) were used to obtain access to condylar region. ${ }^{10}$

There are many systems of fixation have been described such as intraosseous wiring, kirschner wires, lag screws and miniplates although the later is the preferred technique today. Miniplate osteosynthesis provides rigid fixation that could be easily adapted to the curvature of the bone and requires only simple operation. ${ }^{11}$

Choi and Yoo compared the biomechanical stability of four different plating techniques in mandibles from formalin fixed cadavers (4-screw monocortical miniplate, 4-screw bicortical mini dynamic compression plate, 4-screw 2.4 $\mathrm{mm}$ plate and a double monocortical miniplate) . They stated that the double miniplate (double-plate technique) are the most reliable because these neutralize tension and pressure forces best and produce greater stability, but fixation with two miniplates might be a more traumatic procedure than fixation with a single miniplate and two miniplates require a certain size of the proximal condyle fragment and thus are applicable mainly in cases involving low fractures. It also includes use of excess armamentarium and an increased exposure of the condylar region. ${ }^{12-14}$

The 3-dimensional osteosynthesis plates were introduced into maxillofacial surgery in the early 1990s. Advantages are the smaller size combined with greater stiffness of the plates. Specially designed plates such as the delta plate or the trapezoid plate are available and alternative to the double miniplates technique. Biomechanical and clinical studies have confirmed that these plates allow for sufficient neutralization of strains. ${ }^{15}$

\section{MATERIALS AND METHODS}

This is a prospective, single armed case series study that was carried out on twelve patients with displaced low subcondylar mandibular fracture. Open reduction and internal fixation was utilized to treat those fractures using rhombic $3 \mathrm{D}$ plate, patients were collected from the department of Oral and Maxillofacial surgery, Faculty of Dentistry, Tanta University. All patients signed an informed consent before undergoing the surgery. The study was ethically cleared by the research ethical committee.

To qualify for surgery, patients were required to fulfil the following criteria: 1- Medically fit patients free from relevant conditions contraindicating surgery. 2- Patients aged above 16 years old. 3-Patients suffering from displaced low subcondylar mandibular fracture indicated for open reduction. Patients with relevant bone diseases or infected fracture site were excluded from the study.

\section{Materials:}

In this study, the plate which used for fixation of subcondylar mandibular fracture was the 3-dimensional rhombic plate (KLS Martin, Tuttlingen, Germany), which is manufactured of pure titanium (grade 2) of 1.0 $\mathrm{mm}$ thickness and secured with 5 screws of $2.0 \mathrm{~mm}$ head diameter. Also the plate has a unique feature of two gliding holes.

\section{Methods:}

\section{A) Pre-operative Phase:}

For all cases thorough history taking, clinical and radiographic examination were performed.

All patients were subjected to full clinical examination by inspection and palpation of the fracture sites both extraorally and intra-orally to detect the presence of edema, ecchymosis, soft tissue laceration, haemorrhage, site of fracture, dentition, derangement of occlusion, areas of tenderness, step deformities, mobility of fractured segments.

Radiographic examination was accomplished for all patients at the time of presentation. Digital panorama, axial, coronal, 3D reconstruction computerized tomography (CT) were taken for all patients.

\section{B) Operative Phase:}

The surgery was carried out under general anaesthesia with nasal intubation. Intermaxillary fixation (IMF) was done to provide proper occlusion before plate fixation. In order to expose the fracture, a retromandibular approach was made. The incision was made $2 \mathrm{~cm}$ posterior to the posterior border of the ramus of the mandible and 0.5 $\mathrm{cm}$ below the ear lobe. After incision, the parotid gland was separated from the sternocleidomastoid muscle and retracted superiorly. Sub periosteal dissection with stripping the masseter muscle off of the ramus was then performed to expose the fracture site. After the localization of the fracture, the proximal fragment is reduced to the correct anatomical position and fixed using rhombic $3 \mathrm{D}$ plate. The holes were than drilled and the plate fixed in place using 5 screws with $2 \mathrm{~mm}$ head diameter and $7 \mathrm{~mm}$ in length. After checking the correct reduction of the fracture and the stability of the internal fixation, the IMF was removed and the wound was closed in layers using polyglygolic polylactic 30 - suture material (Vicryl, Ethicon, Cornelia, GA, USA) for deep layers and 40- polypropylene suture material (Prolene, Ethicon, Cornelia, GA, USA) for skin layer (Pterygomasseteric sling, platysma, subcutaneous tissue and skin). 


\section{Protrusion movement by millimeters (mm)}

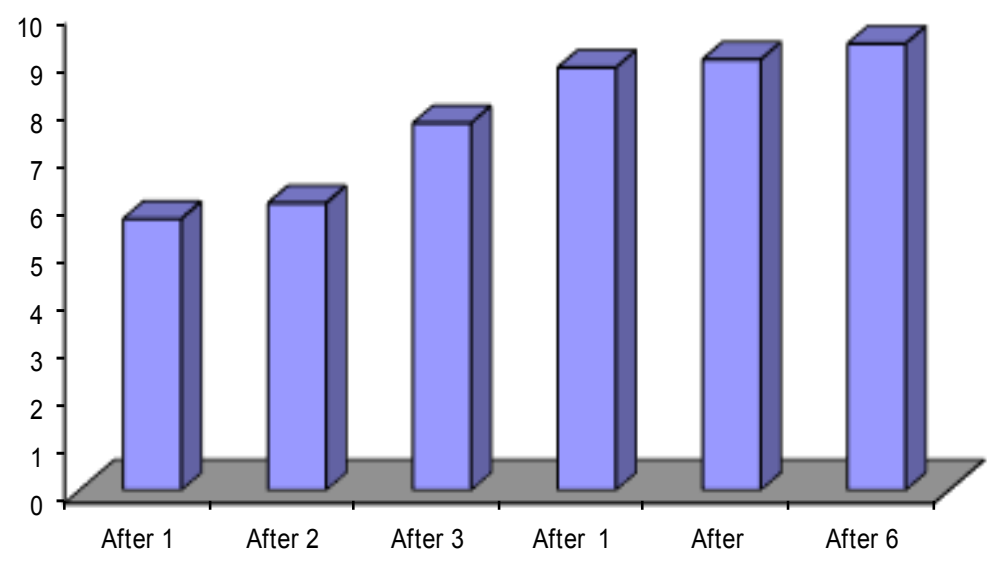

Fig. (1): Column chart showing changes in protrusive movement in all follow up periods.

\section{C) Postoperative Phase:}

Antibiotic schedule was prescribed post-operatively for 5 days, Amoxicillin/Clavulanate potasium $1 \mathrm{gm}$ IV twice daily, (Augmentin, GlaxoSmithKline, Brentford, London). In addition to anti-inflammatory drug, Diclofenac sodium $75 \mathrm{mg}$ IV (Cataflam, Novartis, Basel, Switzerland). All patients were advised to stick to postoperative care instructions to prevent postoperative complications. Dressing change was done by nursing staff on daily bases. Sutures were removed after 5 to 7 days.

\section{D) Follow-up Phase:}

Clinical follow-ups were carried out in all patients after 1 week, 2 weeks, 3 weeks, 1 month, 3 months and 6 months. The follow-ups comprised an analysis of the occlusion, chewing according to ulgesic et al. ${ }^{16}$ questionnaire, the movement of the mandible in all three planes, joint function according to helkimo ${ }^{17}$ index, surgical wound for any signs of infection and any signs of facial nerve injury.

Radiographic studies were carried out using digital panorama, computed tomography (CT) immediately postoperative to check proper reduction and 1 month, 3 and 6 months to detect any cases of non-union, plate fracture, loosening of plate and screws. Vertical height of the ramus and antero-posterior angulation of the condyle was measured using digital panorama as proposed by Silvennoinen et al.18 during all follow up period. Readings were taken each time and then the average was calculated.

\section{Statistical Analysis:}

Statistical analysis was done using SPSS program (SPSS Inc. Released 2008. SPSS Statistics for Windows,
Version 17.0. Chicago: SPSS Inc.) P value was calculated and data was collected $\&$ tabulated.

\section{RESULTS}

\section{Clinical evaluation}

This study included twelve patients with ages ranging from 18 to 55 years with an average of 29 years. The male to female ratio of the total of patients' material was 5:1 (10 men $(83.3 \%)$ and 2 women $(16.7 \%))$

All patients were presented with unilateral displaced low subcondylar fractures. 8 patients were presented with right subcondylar fractures and 4 patients showed left subcondylar fractures. In 11 patients the subcondylar fracture was associated with other mandibular fractures and only one patient had an isolated subcondylar fracture. Regarding the intraoperative experience, the application of the rhombic 3D plate was easier and required minimal manipulation to the soft tissue. None of the patients had non-union, plate fracture, loosening of plate and screws, infection of the surgical wound or facial nerve injury within the follow up period and all patients had satisfactory occlusion, normal chewing throughout the study period.

In all the 12 patients, the maximum mouth opening was between 38 to $48 \mathrm{~mm}$ with average $43.67 \mathrm{~mm}$. (Table 1). The protrusion was between $6 \mathrm{~mm}$ and $11 \mathrm{~mm}$ with average, $9.33 \mathrm{~mm}$. (Table 2, figure 1). The results of the lateral movement showed no significant differences between the contralateral and fractured sides, so that symmetry of the lateral movements was observed. The lateral movement was between $6 \mathrm{~mm}$ and11 $\mathrm{mm}$ with average, $9.3 \mathrm{~mm}$. (Table 3, figure 2). 
Table (1): Showing changes in MMO in all follow up periods.

\begin{tabular}{|c|c|c|c|c|}
\hline $\begin{array}{l}\text { Maximal mouth opening } \\
\text { by millimetres }(\mathrm{mm})\end{array}$ & Range & Mean \pm S. D & t. test & p. value \\
\hline After 1 week & $32-38$ & $33.63 \pm 1.60$ & & \\
\hline After 2 weeks & $34-40$ & $36.17 \pm 1.85$ & 3.602 & $0.002 *$ \\
\hline After 3 weeks & $35-41$ & $38.33 \pm 2.23$ & 2.591 & $0.017 *$ \\
\hline After 1 month & $37-44$ & $41.08 \pm 2.19$ & 3.046 & $0.006^{*}$ \\
\hline After 3months & $37-45$ & $42.38 \pm 2.51$ & 1.341 & 0.194 \\
\hline After 6 months & $38-48$ & $43.67 \pm 2.74$ & 1.203 & 0.242 \\
\hline
\end{tabular}

P: $\mathrm{p}$ values for Student t-test for comparing between follow up periods.

*: Statistically significant at $\mathrm{p} \leq 0.05$

Table (2): Showing changes in protrusion movement in all follow up periods.

\begin{tabular}{|c|c|c|c|c|}
\hline $\begin{array}{l}\text { Protrusion movement } \\
\text { by millimetres }(\mathrm{mm})\end{array}$ & Range & Mean \pm S. D & t. test & p. value \\
\hline After 1 week & $4-8$ & $5.67 \pm 1.15$ & & \\
\hline After 2 weeks & $4-9$ & $6.17 \pm 1.51$ & 0.304 & 0.764 \\
\hline After 3 weeks & $5-9$ & $7.67 \pm 1.23$ & 3.856 & $0.001 *$ \\
\hline After 1 month & $7-10$ & $8.83 \pm 1.03$ & 2.518 & $0.020 *$ \\
\hline After 3months & $6-11$ & $9.00 \pm 1.41$ & 0.330 & 0.745 \\
\hline After 6 months & $6-11$ & $9.33 \pm 1.56$ & 0.549 & 0.589 \\
\hline
\end{tabular}

P: $\mathrm{p}$ values for Student $\mathrm{t}$-test for comparing between follow up periods.

*: Statistically significant at $\mathrm{p} \leq 0.05$

Table (3): Showing changes in lateral movement in all follow up periods.

\begin{tabular}{|c|c|c|c|c|}
\hline $\begin{array}{l}\text { Lateral movement by } \\
\text { millimeters }(\mathrm{mm})\end{array}$ & Range & Mean \pm S. D & t. test & p. value \\
\hline After 1 week & $4-8$ & $5.42 \pm 1.16$ & & \\
\hline After 2 weeks & $5-9$ & $6.17 \pm 1.27$ & 1.510 & 0.145 \\
\hline After 3 weeks & $5-9$ & $7.67 \pm 1.23$ & 2.940 & $0.008^{*}$ \\
\hline After 1 month & $6-10$ & $8.83 \pm 1.11$ & 2.434 & $0.024 *$ \\
\hline After 3 months & $6-11$ & $9.00 \pm 1.41$ & 0.321 & 0.752 \\
\hline After 6 months & $6-11$ & $9.33 \pm 1.56$ & 0.549 & 0.589 \\
\hline
\end{tabular}

P: $p$ values for Student t-test for comparing between follow up periods.

*: Statistically significant at $\mathrm{p} \leq 0.05$

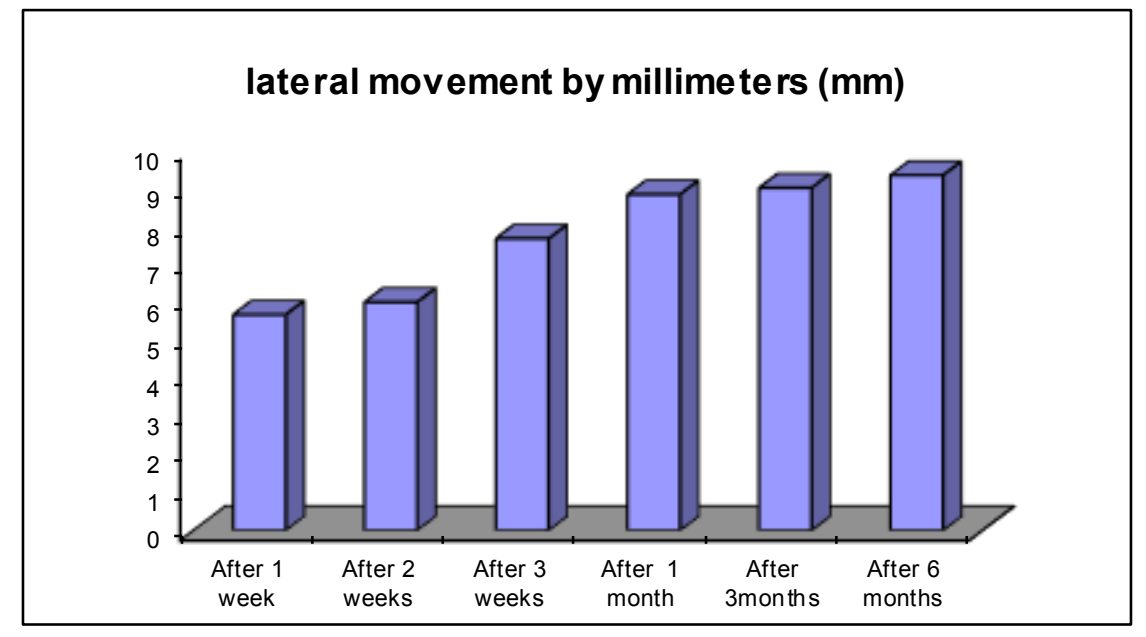

Fig. (2): Column chart showing changes in lateral movement in all follow up periods. 
Mandibular mobility index showed 11 patients $(91.7 \%)$ who were classified as E0 (normal mandibular mobility), only 1 patients $(8.3 \%)$ was E1 (slightly impaired mobility) (Table 4). The Helkimo Index showed 11 patients (91.7\%) who were classified as D0 (free of symptoms), 1 patients $(8.3 \%)$ as D I (mild dysfunction) (Table 5).

Table (4): Assessment of mandibular mobility index.

\begin{tabular}{cccc}
\hline \multicolumn{2}{c}{ Mandibular mobility index } & $\mathrm{N}$ & $\%$ \\
\hline E 0 & Normal mandibular mobility & 11 & $91.7 \%$ \\
E 1 & Slightly impaired mobility & 1 & $8.3 \%$ \\
E 5 & Severely impaired mobility & 0 & $0 \%$ \\
\hline
\end{tabular}

Table (5): Assessment of Helkimo index of dysfunction in all follow up periods.

\begin{tabular}{cccc}
\hline & Helkimo index of dysfunction & N & $\%$ \\
\hline D 0 & Free of symptoms & 11 & $91.7 \%$ \\
D I & Signs of slight dysfunction & 1 & $8.3 \%$ \\
D II & Signs of moderate dysfunction & 0 & $0 \%$ \\
D III & Signs of severe dysfunction & 0 & $0 \%$ \\
\hline
\end{tabular}

\section{Radiographical evaluation}

There was a minor displacement of the fragment and decrease of the mandibular ramus height which reflect the effectiveness in terms of the stability of the fixation observed in our study. This means that the fixation of the plates along an ideal osteosynthesis line enables effective

Table (6): Showing changes in measurements of vertical height of the ramus in all follow up periods.

\begin{tabular}{ccccc}
\hline $\begin{array}{c}\text { Vertical height } \\
\text { of the ramus }\end{array}$ & Range & Mean \pm S. D & t. test & p. value \\
\hline Immediate post-operative & $58-83$ & $71.39 \pm 7.91$ & & 0.886 \\
After 1 month & $57.8-82.2$ & $70.93 \pm 7.81$ & 0.146 & 1.0 \\
After 3 month & $57.8-82.2$ & $70.93 \pm 7.81$ & 0.0 & 1.0 \\
After 6 month & $57.8-82.2$ & $70.93 \pm 7.81$ & 0.0 & \\
\hline
\end{tabular}

P: $p$ values for Student $t$-test for comparing between follow up periods.

*: Statistically significant at $\mathrm{p} \leq 0.05$

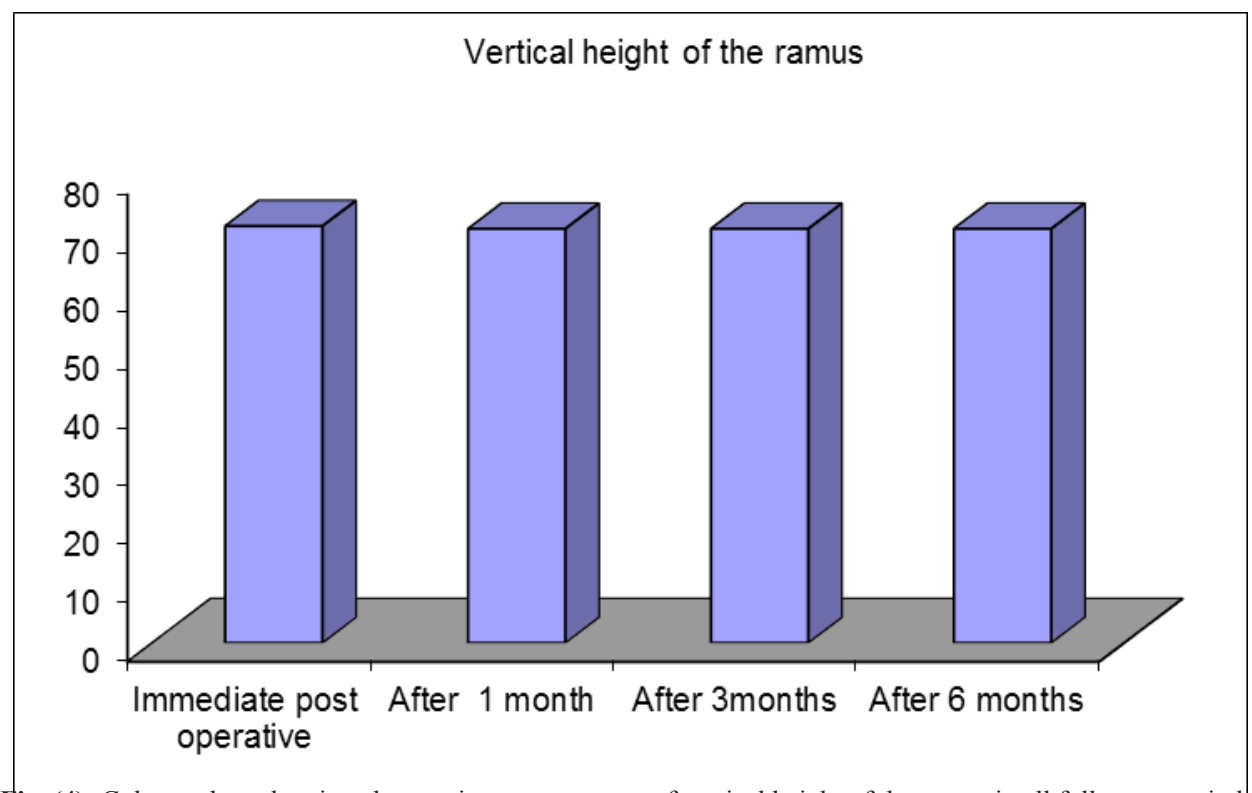

Fig. (4): Columntr chart showing changes in measurements of vertical height of the ramus inr all follow up periocts

Table (7): Showing changes in measurements of Antero-posterior condylar angulation in all follow up periods.

\begin{tabular}{ccccc}
\hline $\begin{array}{c}\text { Antero-posterior } \\
\text { condylar angulation }\end{array}$ & Range & Mean \pm S. D & t. test & p. value \\
\hline Immediate post-operative & $22-35$ & $28.25 \pm 4.05$ & & 0.254 \\
After 1 month & $21.4-34.8$ & $27.83 \pm 4.14$ & 0.0 & 1.0 \\
After 3 month & $21.4-34.8$ & $27.83 \pm 4.14$ & 0.0 & 1.0 \\
After 6 month & $21.4-34.8$ & $27.83 \pm 4.14$ & \\
\hline
\end{tabular}

P: $\mathrm{p}$ values for Student $\mathrm{t}$-test for comparing between follow up periods.

*: Statistically significant at $\mathrm{p} \leq 0.05$ 


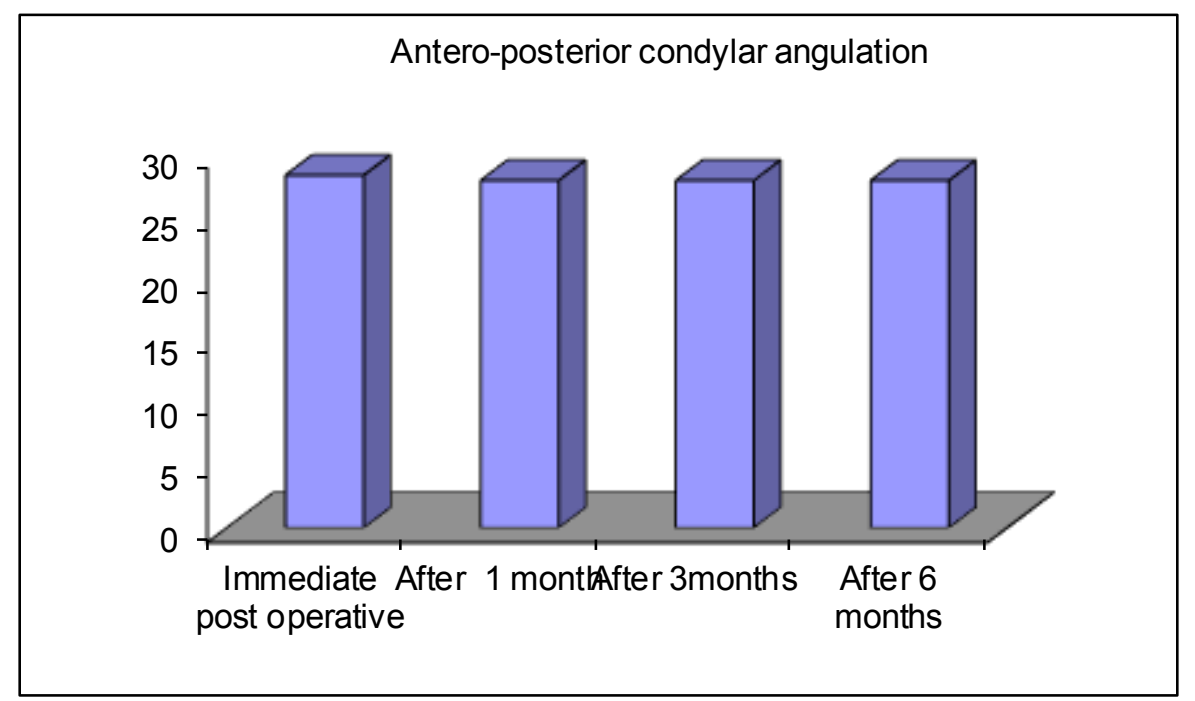

Fig. (5): Column chart showing changes in measurements of Antero-posterior condylar angulation all follow up periods.
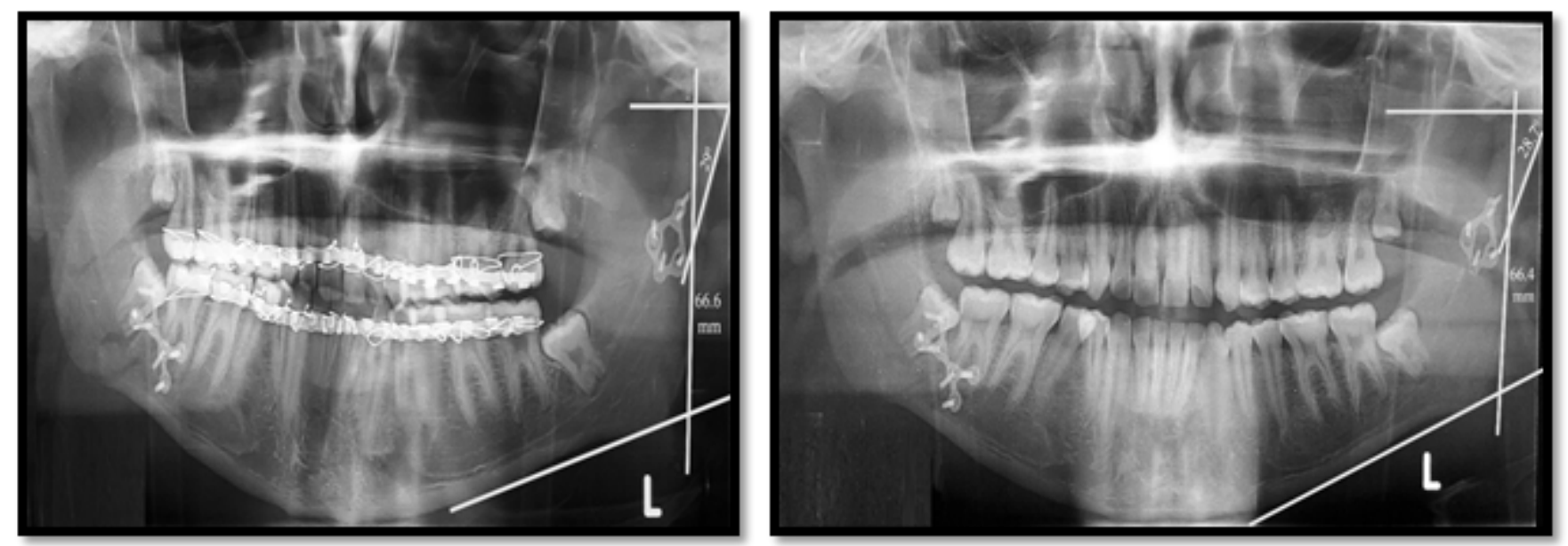

Fig.(6): Immediate postoperative panoramic (Left) photo radiograph showing fixed Rt. subcondylar fracture\& Lt. parasymphysial fracture, six months postoperative panoramic (Right) photo radiograph showing reduction \& fixation Rt. subcondylar fracture\& Lt. parasymphysial fracture.
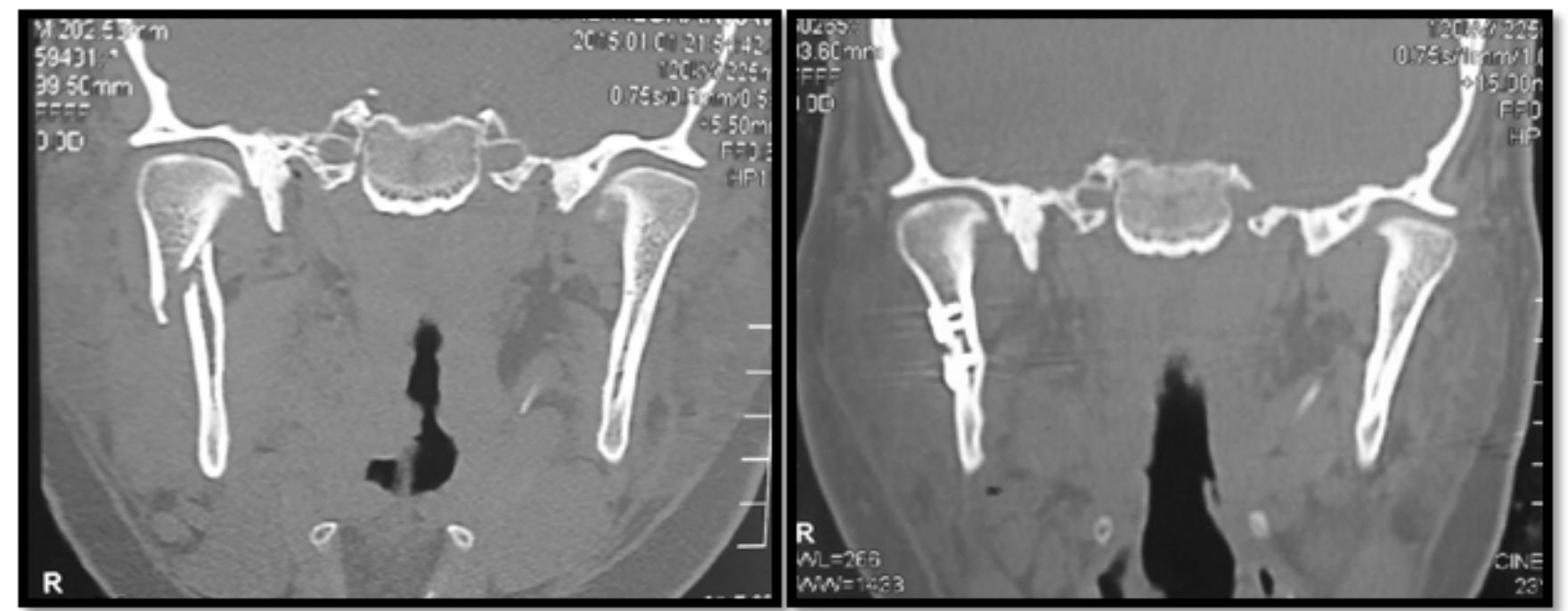

Fig. (7): Preoperative (Left) photo radiograph coronal CT view showing Rt. subcondylar fracture, Postoperative (Right) photo radiograph coronal CT view showing proper reduced \& fixed Rt. subcondylar fracture. 
resistance to the bone tension forces acting on the condylar process during mandibular movements. None of our cases presented with loosening of screws or breaking of the fixation plate. Also there was no disturbance in the fracture healing process. The average postoperative shortening of the ascending ramus height was less than $1 \mathrm{~mm}$ as shown in (Table 6 - Figure 3). The average degree of postoperative displacement of the condyle was less than 10 as shown in (Table 7) (Figure 4 - 7).

\section{DISCUSSION}

The gender distribution in our study shows a clear predominance of males, with a ratio of male $(83.3 \%)$ to female $(16.7 \%)$ of $5: 1$; this is inconsistent with Bormann et al. 19. This ratio demonstrates the more susceptibility of males to trauma due to more physical activity.

The evaluation of the concomitant fractures in our study showed $8.3 \%$ of isolated condylar fracture and $91.7 \%$ with additional mandibular fractures. This ratio explaines that the condylar fractures were the result of the exertion of force which is not fully absorbed in the area of its primary application and leads to extreme bending of the mandibular neck which is the weakest point in the mandible, Zachariades et al.1,Villarreal et al. ${ }^{20}$ described similar fracture distributions.

From our experience, early surgical intervention (not more than 5 days from accident) leads to better and effective results. However more time between the accident and surgery is required in cases of associated injuries, instability of vital signs or traumatic swelling. Barker et al.21 performed the surgery with an average of 2.5 days after the accident, whereby about $60 \%$ were treated on the first day, while Landes and Lipphardt 22 classified the operation as urgent and scheduled it on the fifth day at the latest. Recent studies have shown no increase in complications with a delay of repair beyond 24 hours until 7 days. ${ }^{23,24}$

In our sample, stabilization was performed with 3D rhombic condylar fracture plate. This type of osteosynthesis showed none of the plates fractured, none bent or loosened screws during all recall periods, this is due to its rhombus shape which provides internal stability, as well as more optimal leverage that counteract posterior or anterior loads onto the proximal fragment.

Sikora et $\mathrm{al}^{25}$, in their clinical evaluation of Delta plates reported no plate breakage. The same result was obtained by Haim et al ${ }^{26}$ in their research on the biomechanics of Delta plates by their application in 40 porcine mandibles, as well as by Lauer et al. 27 in a 1-year-long observation of 16 patients with all in all 19 Delta plates.

The mean maximal interincisal opening postoperatively was $43.67 \mathrm{~mm}$ (range 38 to $48 \mathrm{~mm}$ with SD $2.74 \mathrm{~mm}$ ). This value is consistent with the results of Landes et al. 28. In our sample, 11 patients $(91.7 \%)$ showed unlimited mouth mobility while only one patient $(8.3 \%)$ showed slight limited mouth opening $(38 \mathrm{~mm})$ because of severely displaced condylar fracture before treatment that leads to a luxation of the mandibular head out of the glenoid fossa, which is associated with joint damage, functional loss of the lateral pterygoid muscle and postoperative scarring occurred during healing of the surgical site. Close explanation was also reported by Palmieri et al., Yang et al. ${ }^{29,30}$

The mean of lateral protrusive movement postoperatively was $10.54 \mathrm{~mm}$ to the fractured side and $10.57 \mathrm{~mm}$ to contralateral side in 11 patients $(91.7 \%)$, which shows statistically non-significant difference. This finding is in consistent with the results of Trost et al.31 who reported that symmetry of the mandibular movement was achieved in $84.4 \%$ of the patients $(31 / 35)$ with less than $2 \mathrm{~mm}$ of homolateral deviation remaining in $15.6 \%$. Our study showed a little reduction in lateral movement and slight restricted anterior movement of less than $7 \mathrm{~mm}$ in only one case (8.3\%), this is may be due to adhesions in the articular cavity, postoperative scarring in the capsular ligament system and disc dislocation. This is also reported by Hlawitschka et al. ${ }^{32}$

Regarding facial nerve injury, none of the patients in our study showed any signs of facial nerve injury throughout the follow up period. Our experience indicates that this procedure requires careful surgery with careful blunt dissection of the soft tissue layers including parotid capsule so that the nerve can be protected and retracted, and also avoid prolonged traction on the operated site. However, Sikora et al ${ }^{25}$ in their study diagnosed $7 \%$ of the patients during the postoperative period with a partial paresis of the facial nerve; in each of these cases, the correct function of the facial nerve returned spontaneously 3 months after the surgery.

The Helkimo index in our study showed that $91.7 \%$ of patients have a low score of D0 (symptom-free), 1 patient $(8.3 \%)$ had D I (slight dysfunction). Eulert et al. 33 found absence of dysfunction D0 in $67.5 \%$ of surgically operated patients $(34 / 51)$. Also Schneider et al.34 pointed out that $70 \%$ of patients $(17 / 25)$ were symptom-free.

Similar to the data reported by Ellis et al. ${ }^{35}$ and Vesnaver et $\mathrm{al}^{36}$, in our series the average reduction of the mandibular ramus length of less than $1 \mathrm{~mm}$ was calculated and the average degree of postoperative displacement of the condyle was less than 10 throughout the follow up period.

Although this still needs to be tested biomechanically, the radiographic results of this study suggests that the modification of the 3 sided triangular pattern in the delta plate to a 4 sided rhombus form in the rhombus plate together with the effect of compression provided by the gliding holes provides us with a plate with higher stability than the 2 miniplates.

\section{CONCLUSIONS}

In conclusion, the application of the three dimensional rhombic plate for the stable osteosynthesis of condylar fractures ensures fully satisfactory treatment results, both from the clinical and radiological points of view. 


\section{REFERENCES}

1. Zachariades N, Mezitis M, Mourouzis C, Papadakis D, Spanou A. Fractures of the mandibular condyle: a review of 466 cases. Literature review, reflections on treatment and proposals. Journal of CranioMaxillofacial Surgery. 2006 Oct 31; 34(7):42132-.

2. Sawazaki R, Júnior SM, Asprino L, Moreira $\mathrm{RW}$, De Moraes M. Incidence and patterns of mandibular condyle fractures. Journal of Oral and Maxillofacial Surgery. 2010 Jun 30; 68(6):12529-.

3. Valiati R, Ibrahim D, Abreu Me, Heitz C, De Oliveira $\mathrm{Rb}$, Pagnoncelli Rm, Silva Dn. The treatment of condylar fractures: to open or not to open? A critical review of this controversy. International journal of medical sciences. 2008; 5(6):313.

4. Rozeboom AV, Dubois L, Bos RR, Spijker R, de Lange J. Open treatment of condylar fractures via extraoral approaches: a review of complications. Journal of Cranio-Maxillofacial Surgery. 2018 May 18.

5. Van Hevele J, Nout E. Complications of the retromandibular transparotid approach for low condylar neck and subcondylar fractures: a retrospective study. Journal of the Korean Association of Oral and Maxillofacial Surgeons. 2018 Apr 1;44(2):738-.

6. Pickrell BB, Serebrakian AT, Maricevich RS. Facial Trauma: Mandible Fractures. InSeminars in plastic surgery 2017 May (Vol. 31, No. 2, p. 100). Thieme Medical Publishers.

7. Singh V, Bhagol A, Goel M, Kumar I, Verma A. Outcomes of open versus closed treatment of mandibular subcondylar fractures: a prospective randomized study. Journal of Oral and Maxillofacial Surgery. 2010 Jun 30; 68(6):13049-.

8. Haug RH, Allaire M, Trangoni K. Parameters and pathways: clinical practice guidelines for oral and maxillofacial surgery. Chicago: American Association of Oral and Maxillofacial Surgeons. 2001.

9. Zide MF, Kent JN. Indications for open reduction of mandibular condyle fractures. Journal of Oral and Maxillofacial Surgery. 1983 Feb 28; 41(2):8998.

10. Vesnaver A, Gorjanc M, Eberlinc A, Dovšak DA, Kansky AA. The periauricular transparotid approach for open reduction and internal fixation of condylar fractures. Journal of Cranio-Maxillofacial Surgery. 2005 Jun 30; 33(3):16979-.

11. Assael LA. Open versus closed reduction of adult mandibular condyle fractures: an alternative interpretation of the evidence. Journal of oral and maxillofacial surgery. 2003 Nov 30; 61(11):13339-.
12. Choi BH, Yoo JH. Clinical evaluation of 3 types of plate osteosynthesis for fixation of condylar neck fractures. Journal of oral and maxillofacial surgery. 2001 Jul 31; 59(7):7347-.

13. Noda M, Kawashima Y, Tokunaga S, Ito K, Hara Y, Hirahara N, Sawada E, Iizuka N, Kaneda T. Risk Assessment for Condylar Fracture Using Classification of the Mandibular Inferior Cortical Shape by Pantomography. International Journal of Oral-Medical Sciences. 2018 Mar 2; 16(3-49:(453.

14. Cavalieri-Pereira L, Spagnol G, Sverzut CE, de Moraes M, Trivellato AE. Resistance of four fixation techniques used to treat subcondylar fractures. Oral and maxillofacial surgery. 2018 Jan $17: 16-$.

15. Akdag O, Yildiran G, Abaci M, Tosun Z. Endoscopic-Assisted Treatment Combined With Transoral and Transbuccal Approach to Mandibular Subcondylar Fractures. Journal of Oral and Maxillofacial Surgery. 2017 Dec 5:15-.

16. Uglešić $V$, Virag $M$, Aljinović $N$, Macan $D$. Evaluation of mandibular fracture treatment. Journal of Cranio-Maxillofacial Surgery. 1993 Sep 30; 21(6):2517-.

17. Helkimo M. Studies on function and dysfunction of the masticatory system. 3. Analyses of anamnestic and clinical recordings of dysfunction with the aid of indices. Svensk tandlakare tidskrift. Swedish dental journal. 1974 May; 67(3):16581-.

18. Silvennoinen U, Iizuka T, Oikarinen $\mathrm{K}$, Lindqvist C. Analysis of possible factors leading to problems after nonsurgical treatment of condylar fractures. Journal of oral and maxillofacial surgery. 1994 Aug 31; 52(8):7939-.

19. Bormann KH, Wild S, Gellrich NC, Kokemüller H, Stühmer C, Schmelzeisen R, Schön R. Fiveyear retrospective study of mandibular fractures in Freiburg, Germany: incidence, etiology, treatment, and complications. Journal of Oral and Maxillofacial Surgery. 2009 Jun 30;67(6):12515-.

20. Villarreal PM, Monje F, Junquera LM, Mateo J, Morillo AJ, González C. Mandibular condyle fractures: determinants of treatment and outcome. Journal of oral and maxillofacial surgery. $2004 \mathrm{Feb}$ 29; 62(2):15563-.

21. Barker DA, Oo KK, Allak A, Park SS. Timing for repair of mandible fractures. The Laryngoscope. 2011 Jun 1;121(6):11603-. 
22. Landes CA, Lipphardt R. Prospective evaluation of a pragmatic treatment rationale: open reduction and internal fixation of displaced and dislocated condyle and condylar head fractures and closed reduction of non-displaced, non-dislocated fractures: Part I: condyle and subcondylar fractures. International journal of oral and maxillofacial surgery. 2005 Dec 31; 34(8):85970-.

23. Webb LS, Makhijani S, Khanna M, Burstein MJ, Falk AN, Koumanis DJ, Chao JD. A comparison of outcomes between immediate and delayed repair of mandibular fractures. Canadian Journal of Plastic Surgery. 2009 Dec;17(4):1246-.

24. Biller JA, Pletcher SD, Goldberg AN, Murr $\mathrm{AH}$. Complications and the time to repair of mandible fractures. The Laryngoscope. 2005 May 1;115(5):76972-.

25. Sikora M, Sielski M, Stąpor A, Chlubek D. Use of the Delta plate for surgical treatment of patients with condylar fractures. J Craniomaxillofac Surg. 2016; 44(7):7704-.

26. Haim D, Müller A, Leonhardt H, Nowak A, Richter G, Lauer G. Biomechanical study of the Delta plate and the Tri Lock Delta condyle trauma plate. J Oral Maxillofac Surg. 2011; 69: 261925-.

27. Lauer G, Haim D, Proff P, Ritcher G, Pardel W, Fanghanel J Et al. Plate osteosynthesis of the mandibular condyle. Ann Anat. 2007;189: 4127-.

28. Landes CA, Day K, Lipphardt R, Sader R. Prospective closed treatment of nondisplaced and nondislocated condylar neck and head fractures versus open reposition internal fixation of displaced and dislocated fractures. Oral and maxillofacial surgery. 2008 Jul 1;12(2):7988-

29. Palmieri C, Ellis E, Throckmorton G. Mandibular motion after closed and open treatment of unilateral mandibular condylar process fractures. Journal of oral and maxillofacial surgery. $1999 \mathrm{Jul}$ 31; 57(7):76475-
30. Yang WG, Chen CT, Tsay PK, Chen YR. Functional results of unilateral mandibular condylar process fractures after open and closed treatment. Journal of Trauma and Acute Care Surgery. 2002 Mar 1;52(3):498503-.

31. Trost O, Trouilloud P, Malka G. Open reduction and internal fixation of low subcondylar fractures of mandible through high cervical transmasseteric anteroparotid approach. Journal of Oral and Maxillofacial Surgery. 2009 Nov 30;67(11):244651.

32. Hlawitschka M, Loukota R, Eckelt U. Functional and radiological results of open and closed treatment of intracapsular (diacapitular) condylar fractures of the mandible. International journal of oral and maxillofacial surgery. 2005 Sep 30;34(6):597604-.

33. Eulert S, Proff P, Bokan I, Blens T, Gedrange T, Reuther J, Bill J. Study on treatment of condylar process fractures of the mandible. Annals of Anatomy-Anatomischer Anzeiger. 2007 Jul 11; 189(4):37783-

34. Schneider M, Erasmus F, Gerlach KL, Kuhlisch E, Loukota RA, Rasse M, Schubert J, Terheyden $\mathrm{H}$, Eckelt U. Open reduction and internal fixation versus closed treatment and mandibulomaxillary fixation of fractures of the mandibular condylar process: a randomized, prospective, multicenter study with special evaluation of fracture level. Journal of Oral and Maxillofacial Surgery. 2008 Dec 31; 66(12):253744-.

35. Ellis E, Throckmorton GS. Treatment of mandibular condylar process fractures: biological considerations. Journal of oral and maxillofacial surgery. 2005 Jan 31; 63(1):11534-.

36. Vesnaver A, Ahčan U, Rozman J. Evaluation of surgical treatment in mandibular condyle fractures. Journal of Cranio-Maxillofacial Surgery. 2012 Dec 31; 40(8):64753-. 